\title{
Amyloid in osteoarthritic hip joints: deposits in relation to chondromatosis, pyrophosphate, and inflammatory cell infiltrate in the synovial membrane and fibrous capsule
}

\author{
CHR. LA DEFOGED \\ From the Institute of Pathology, Odense University Hospital, Odense, Denmark
}

SUMMARY The relationship between osteoarthritic change and amyloid degeneration was studied in 116 joint capsules from osteoarthritic hip joints. Twenty-seven (23\%) contained amyloid deposits. Twenty-eight joint capsules showed chondroid metaplasia in the fibrous part. Significantly more amyloid degeneration was found among these. Six joint capsules contained pyrophosphate crystals. Five of these were positive for amyloid. Chronic inflammation of the joint capsule was found in $80 \%$ of the cases and was negatively correlated with amyloid degeneration, which is in good agreement with the biphasic theory for the pathogenesis of amyloid. Further investigation is necessary to decide how chondroid metaplasia takes part in the production of amyloid.

In 1972 Christensen and Sørensen ${ }^{1}$ published 17 cases of amyloid degeneration in hip joint capsules. The cases were from an unselected series consisting of 43 patients operated on for severe osteoarthritis coxae ( 46 capsules). This seems to be the first histological investigation of the correlation between amyloidosis and osteoarthritis.

This paper describes amyloid deposits in the fibrous part of the capsule from osteoarthritic hip joints in relation to secondary chondromatosis, pyrophosphate deposits, and inflammatory cell infiltration.

\section{Material and methods}

The material for light microscopy comprised approximately $5 \times 3 \times 2 \mathrm{~cm}$ pieces of tissue from the synovial membrane and the fibrous capsule. They were removed at each of 116 consecutive operations for osteoarthritis coxae. Four patients had their hips resected bilaterally.

The average age of the patients was 61 years (range $32-74)$, and 47 of them were women. None had clinical signs of primary amyloidosis, myelomatosis, or tuberculosis. One patient had concurrent

\footnotetext{
Accepted for publication 9 November 1982.
}

Correspondence to $\mathrm{Dr} \mathrm{C}$. Ladefoged, Institute of Pathology, Sønderborg Hospital, 6400 Sønderborg, Denmark. rheumatoid arthritis. The operations were carried out according to the method of Charnley at the department of Orthopaedic Surgery O, of the Odense University Hospital.

The control material consisted of tissue from 25 autopsy hip joint capsules without osteoarthritic changes such as hyaline degeneration, vascular proliferation with perivascular fibrosis, inflammatory cell infiltration, chondroid metaplasia, or calcification. No macroscopic signs of osteoarthritis were seen on the femoral heads. The average age of the patients was 67 years, and 13 capsules were from women. No cases of generalised amyloidosis, rheumatoid arthritis, tuberculosis, or myelomatosis were found in the control material.

The tissue was immediately fixed in $10 \%$ formalin and kept in it for approximately 24 hours. Thereafter representative pieces were removed from both the synovial membrane and the fibrous capsule and embedded in paraffin after dehydration in ethanol and xylene. Sections $6 \mu \mathrm{m}$ thick were then stained with haematoxylin and eosin, alcian blue $8 \mathrm{GX}$, alkaline Congo red, and, in selected cases, van Gieson's connective tissue stain. Amyloid was considered to be specifically demonstrated when the yellowish-red colour of the alkaline Congo red staining showed green dichroism on polarisation microscopy. ${ }^{23}$

Electron microscopy was performed only on the 
material obtained at surgical operation. Small blocks $1 \mathrm{~mm}$ on each side were fixed for 3 hours in $5 \%$ glutaraldehyde in cacodylate buffer. They were then rinsed in $10 \%$ sucrose in cacodylate buffer and postfixed in $1 \%$ osmium tetroxide for 2 hours. After this they were dehydrated in alcohol and propylene oxide, embedded in Epon, and cut on an ultramicrotome (Reichert). The ultrastructural studies were carried out on a Philips EM 201 electron microscope.

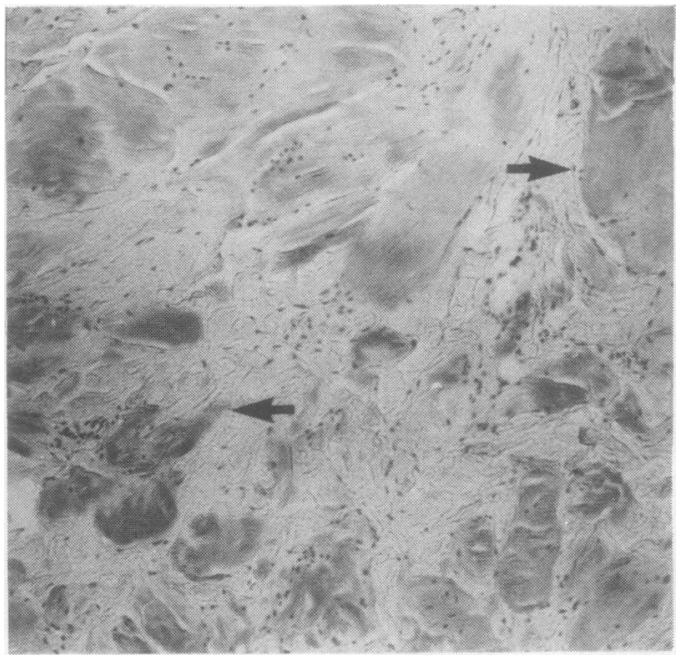

Fig. 1 Joint capsule with massive amyloid deposits (arrows). (Alkaline congo red, $\times 100)$.

\section{Results}

Twenty-seven of the 116 capsules studied (23\%) were positive for amyloid. Ten joint capsules contained slight deposits, 10 moderate, and 7 severe deposits. The material was distributed irregularly in the fibrous part of the capsule, and only few and small deposits where found in the loose subsynovial connective tissue (Fig. 1).

In the capsular tissue from 3 of the 4 patients subjected to bilateral resection no amyloid could be found on either side. One patient showed moderate deposits in the right hip joint capsule and nothing in the left. Ultrastructurally, characteristic connective tissue with parallel and crossing bundles of collagen fibres was found. Between these bundles of collagen fibres deposits of another fibrillar material could be seen. The single fibrils in this material were straight, unbranched, and lying criss-cross to each other. The width varied from 8 to $25 \mathrm{~nm}$ (Fig. 2)-all features which are characteristic of amyloid. ${ }^{4}$ Often the material was deposited close to fibroblasts (Fig. 3).

Of the 25 control capsules without histological osteoarthritic changes only 3 were positive for amyloid-2 with slight and one with moderate degree. When both the number of capsules positive and the degree of deposition are taken into account, this is significantly less amyloid than among the capsules from the osteoarthritic material ( $\chi^{2}$ test, $\mathrm{p}<0.001)$.

Secondary chondromatosis was found in 28 joint capsules in varying degrees of severity (Table 1). In 5

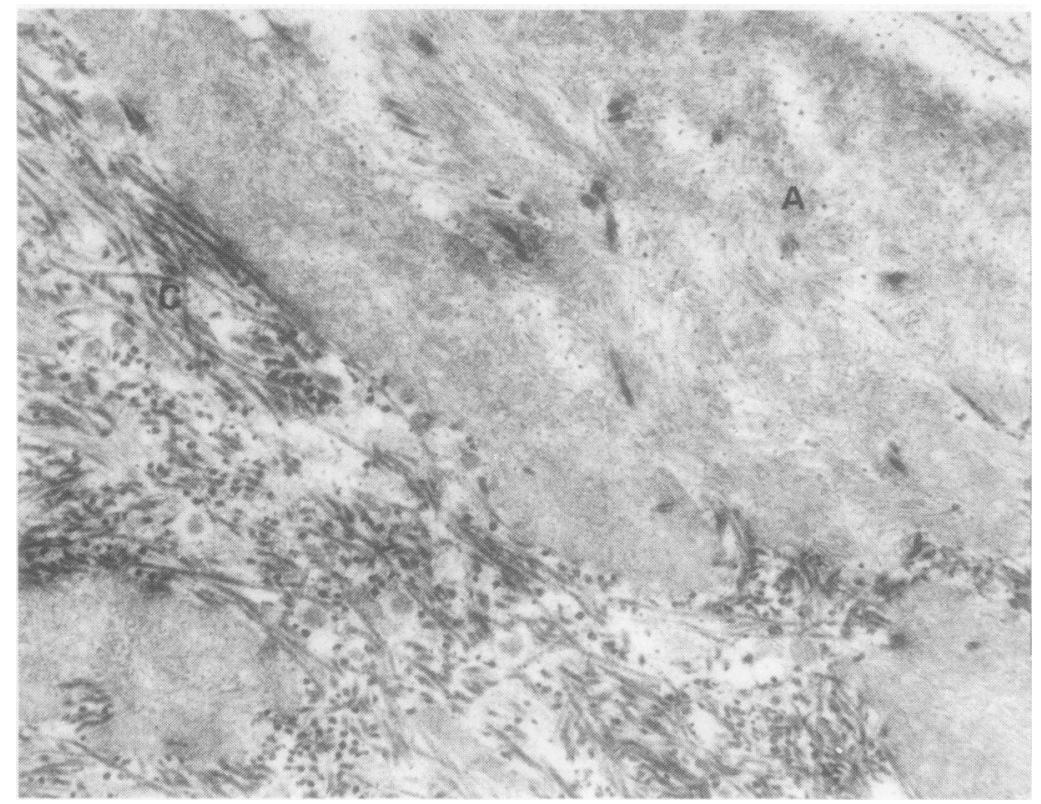

Fig. 2 Electron micrograph of amyloid deposits $(A)$ between collagen bundles $(C)$ in joint capsule. $(\times 10810)$. 


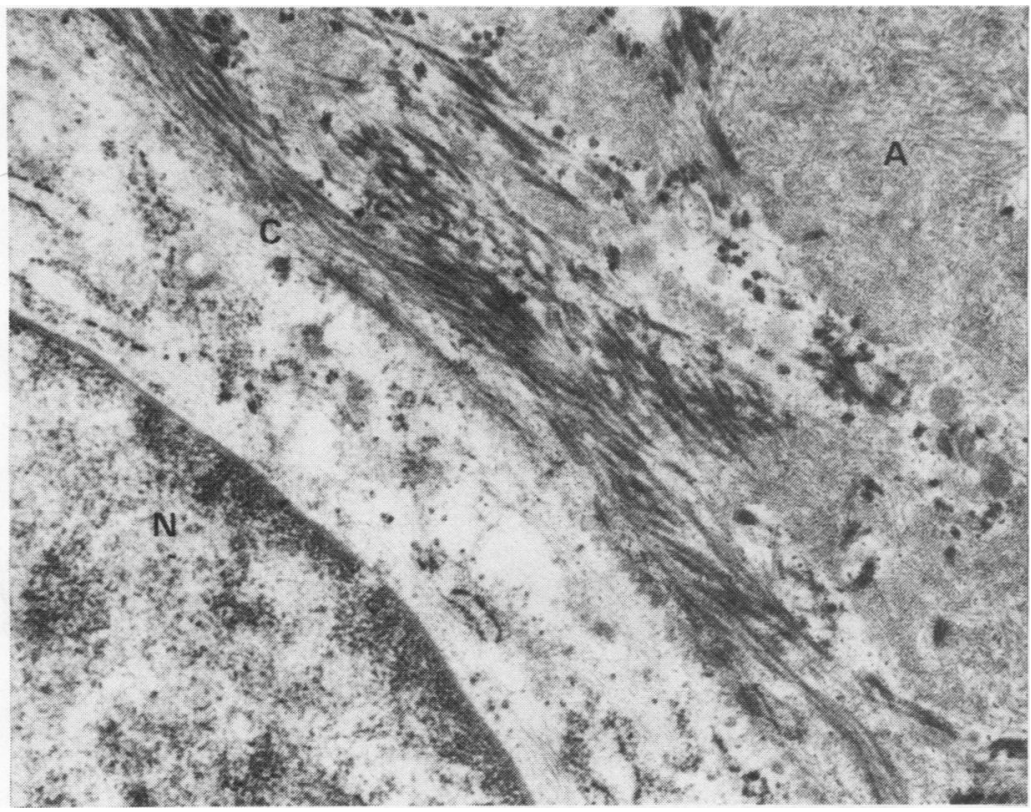

Fig. 3 Amyloid deposits $(A)$ in relation to fibroblast in joint capsule. $C=$ cell membrane, $N=$ nucleus. $(\times 10810)$.

Table 1 Chondroid metaplasia of 28 hip joint capsules and its relationship to pyrophosphate and amyloid deposits.

\begin{tabular}{|c|c|c|c|c|c|}
\hline Case & Sex & Age & $\begin{array}{l}\text { Chondroid } \\
\text { metaplasia }\end{array}$ & $\begin{array}{l}\text { Pyro- } \\
\text { phosphate }\end{array}$ & Amyloid \\
\hline 1 & $\mathbf{M}$ & 71 & +++ & ++ & ++ \\
\hline 2 & $F$ & 73 & ++ & 0 & 0 \\
\hline 3 & $\mathbf{M}$ & 57 & + & 0 & 0 \\
\hline 4 & $\mathbf{M}$ & 67 & +++ & 0 & + \\
\hline 5 & $\mathbf{F}$ & 64 & + & 0 & 0 \\
\hline 6 & $\mathbf{M}$ & 60 & ++ & ++ & +++ \\
\hline 7 & $\mathbf{M}$ & 71 & +++ & +++ & +++ \\
\hline 8 & F & 59 & ++ & 0 & + \\
\hline 9 & $\mathbf{M}$ & 69 & +++ & 0 & ++ \\
\hline 10 & $\mathbf{M}$ & 59 & ++ & 0 & 0 \\
\hline 11 & $\mathbf{M}$ & 50 & + & 0 & 0 \\
\hline 12 & $\mathbf{M}$ & 66 & + & 0 & 0 \\
\hline 13 & $\mathbf{M}$ & 64 & + & 0 & ++ \\
\hline 14 & $\mathbf{M}$ & 49 & ++ & 0 & ++ \\
\hline 15 & $\mathbf{F}$ & 32 & ++ & 0 & 0 \\
\hline 16 & $\mathbf{M}$ & 65 & ++ & 0 & ++ \\
\hline 17 & $\mathbf{F}$ & 66 & + & 0 & ++ \\
\hline 18 & $\mathbf{F}$ & 71 & + & 0 & 0 \\
\hline 19 & $\mathbf{M}$ & 50 & ++ & 0 & ++ \\
\hline 20 & F & 54 & ++ & 0 & 0 \\
\hline 21 & $\mathbf{M}$ & 72 & +++ & ++ & + \\
\hline 22 & $F$ & 64 & ++ & 0 & + \\
\hline 23 & $\mathbf{F}$ & 44 & ++ & 0 & + \\
\hline 24 & $\mathbf{F}$ & 68 & ++ & 0 & ++ \\
\hline 25 & $\mathbf{F}$ & 46 & ++ & ++ & +++ \\
\hline 26 & $\mathbf{M}$ & 72 & ++ & 0 & +++ \\
\hline 27 & $\mathbf{M}$ & 56 & + & 0 & 0 \\
\hline 28 & $\mathbf{M}$ & 68 & ++ & 0 & +++ \\
\hline
\end{tabular}

$0=$ none, + slight,++ moderate, +++ severe degree. cases there was total chondromatous transformation of the joint capsule. The chondromatous parts were commonly found in a position corresponding to the fibrous part of the capsule. However, in a few cases the subsynovial connective tissue was also involved. Often the amyloid was found in half-moon or corona like deposits around the chondrocytes, by the light

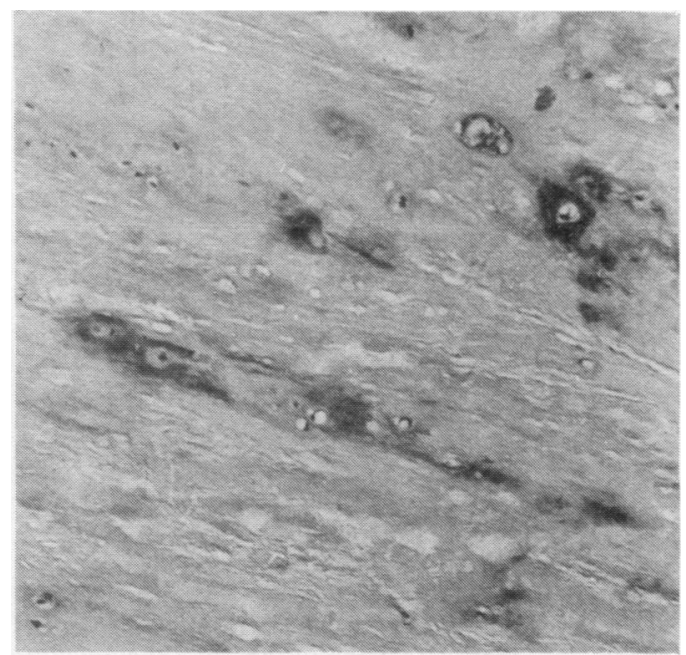

Fig. 4 Joint capsule with chondroid metaplasia. Amyloid is seen closely surrounding the chondrocyte-like cells. (Alkaline congo red, $\times 300)$. 


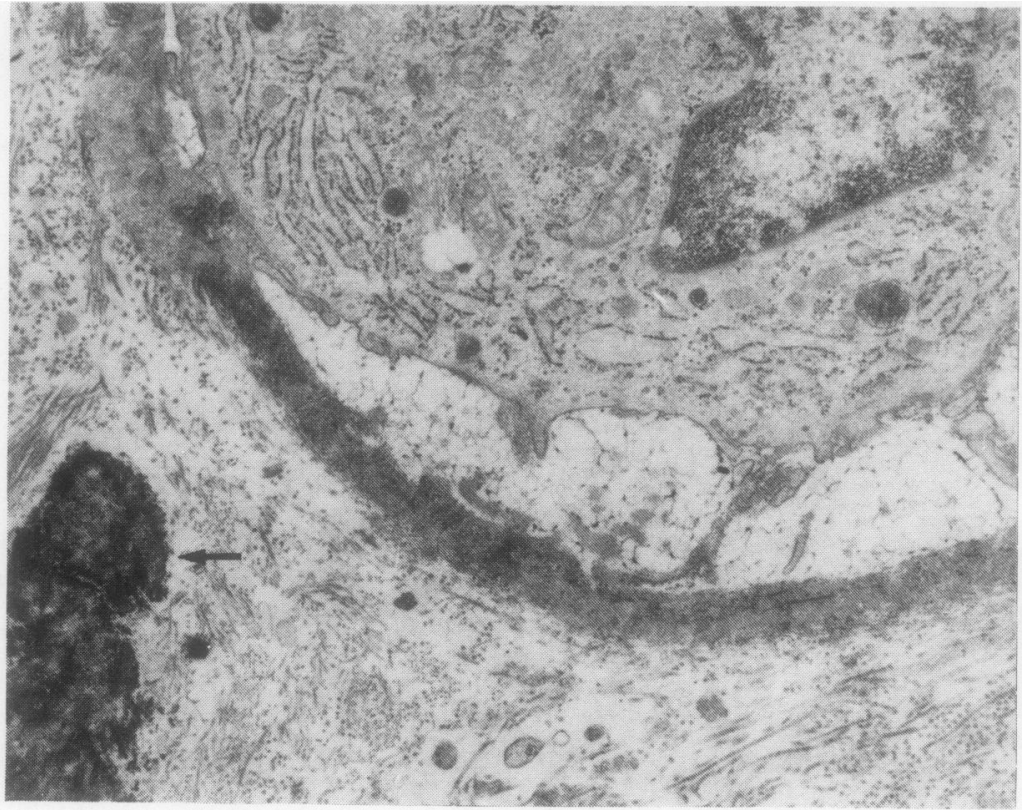

Fig. 5 Dense fibrillar and granular material in corona round a chondrocyte in joint capsule with chondroid metaplasia. Note also calcium phosphate deposits (arrow). $(\times 7210)$.

microscope (Fig. 4) as well as the electron microscope (Fig. 5).

Among the 28 chondromatous joint capsules 18 were positive for amyloid (64\%). This is significantly more than among the capsules without chondromatosis, where amyloid was found in only approximately $10 \%\left(\chi^{2}\right.$ test, $\left.\mathrm{p}<0 \cdot 001\right)$.

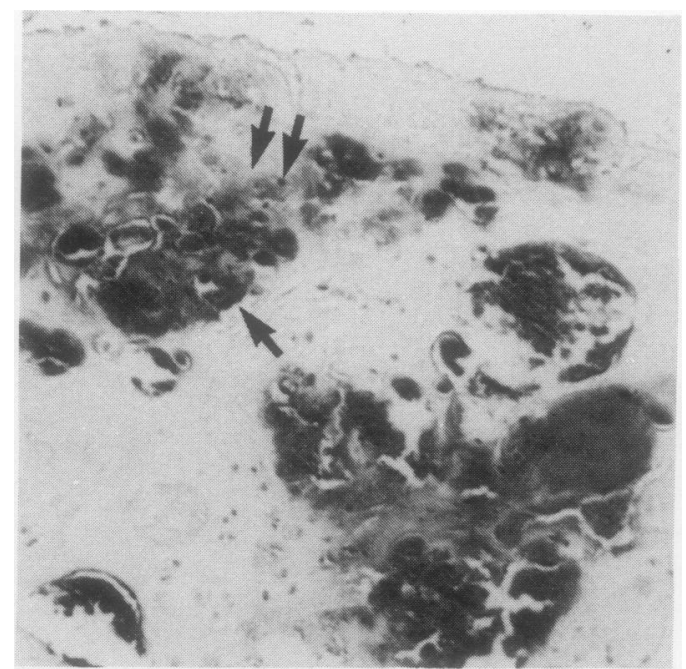

Fig. 6 Joint capsule containing pyrophosphate deposited in the collagen and hyalinised connective tissue (arrow). Amyloid degeneration can be seen close to the pyrophosphate (2 arrows). (Alkaline congo red, $\times 200)$.
Six joints were positive for calcium pyrophosphate $\vec{\varphi}$ crystals. They were often found embedded in hyalinised collagen connective tissue in the fibrous. capsule (Fig. 6). As can be seen from Table 1, both chondromatosis as well as amyloid deposits were found in 5 of the 6 joints with pyrophosphate.

In $93(80 \%)$ of the joint capsules it was possible to

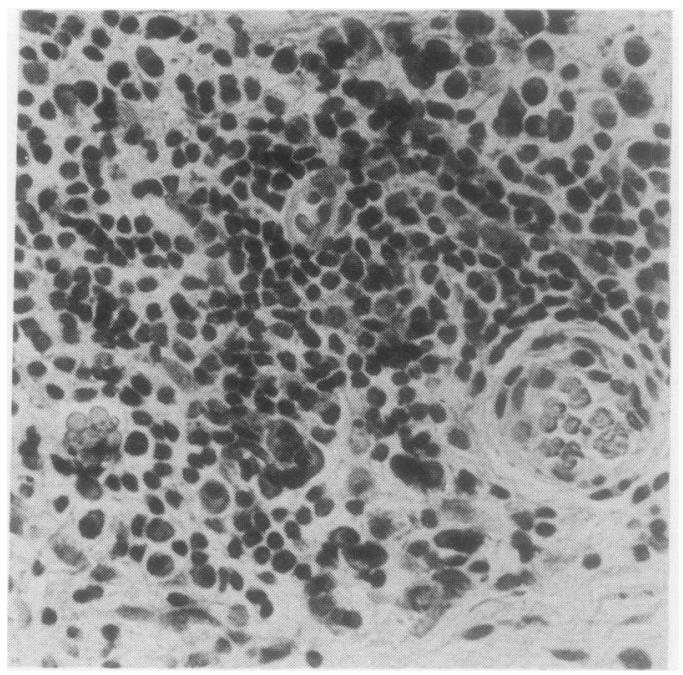

Fig. 7 Joint capsule with subsynovial accumulation of lymphocytes and plasma cells. (Haematoxylin and eosin, $\times 400)$. 
find varying degrees of chronic inflammation. Inflammatory cell infiltration was in most cases concentrated in the loose subsynovial connective tissue (Fig. 7). Only slight diffuse lymphocyte and plasma cell infiltration could be found in one half of the joint capsules, while in $25 \%$ and $5 \%$, respectively, moderately severe and severe infiltration of lymphocytes and severe diffuse plasma cell infiltration could be observed. Among the 23 cases without inflammation 8 were found to be amyloid-positive $(35 \%)$, while only 19 were found to contain amyloid (20\%) among the 93 joint capsules with inflammation.

Hyaline degeneration of the tissue in the fibrous capsule could be found in nearly all the osteoarthritic joint capsules studied. The extent of the hyalinisation was not correlated with amyloid degeneration. Similarly, blood vessel proliferation, congestion in the blood vessels, and perivascular fibrosis were almost always found, but amyloid was rarely deposited in the walls of the blood vessels.

\section{Discussion}

It has long been known that amyloid deposits in the joint capsule can be found in connection with primary amyloidosis, ${ }^{5-7}$ myelomatosis, ${ }^{8-11}$ and rheumatoid arthritis. ${ }^{12-15}$ In the last decade reports have appeared describing amyloid degeneration in the capsules from osteoarthritic hip joints, ${ }^{16}$ and in 1980 we found this substance in hip joint capsules in an unselected series of autopsies. ${ }^{17}$ In the present study $23 \%$ of the capsules were positive for amyloid. The clinical significance of this finding has not yet been investigated. However, some of the heaviest deposits might reduce joint movement.

Chondroid metaplasia, secondary to degenerative disease, is a relatively common finding in joint capsules. ${ }^{18-20}$ In the present work amyloid degeneration was found significantly more frequently in joint capsules with chondroid metaplasia. Tegelbjærg et al. ${ }^{19}$ observed the same relationship between amyloid degeneration and chondromatosis in joint capsule tissue. The finding is furthermore in good agreement with the fact that the joint cartilage is also frequently the seat of amyloid deposits ${ }^{17-21-23}$ and prompts the question whether chondrocytes are involved in the production of amyloid fibrils.

The osteoarthritic material contained significantly more amyloid than the autopsy control material. If the 28 capsules with chondroid metaplasia are removed from the osteoarthritic material, so that only the 88 osteoarthritic capsules without chondromatosis are left, no difference in the amount of amyloid existed between these 88 capsules and the control material. This finding again points to the chondroid tissue as an essential factor in the creation of joint amyloid.
Table 2 Inflammatory cell infiltration in relation to amyloid. This table shows the results from Christensen and Sørensen ${ }^{1}$ (46 hip joint capsules) added to those of the present study. Amyloid is significantly negatively correlated with inflammation of the capsule $(0.02>p>0.01)$

\begin{tabular}{|c|c|c|c|}
\hline \multirow[t]{2}{*}{ Inflammation } & \multicolumn{3}{|l|}{ Amyloid } \\
\hline & Positive & Negative & Total \\
\hline Severe + moderate degree & 9 & 49 & 58 \\
\hline Slight degree + none & 35 & 69 & 104 \\
\hline Total & 44 & 118 & 162 \\
\hline
\end{tabular}

In a study carried out by Bjelle and Sundén ${ }^{24}$ it was found that degenerative disease was present in 6 of 15 patients with pyrophosphate arthritis. Teglbjærg et al. ${ }^{19}$ reported a study of 15 patients with pyrophosphate arthritis, of whom no fewer than 12 had osteoarthritic changes ( 7 in the hip joint and 5 in the knee). In our series $5 \%$ were found to have pyrophosphate deposits. A relationship seems to exist between degenerative joint disease and pyrophosphate arthritis_a relationship the pathogenesis of which is still not clear.

Inflammation of a chronic type was observed in $80 \%$ of the studied joint capsules. Christensen and Sørensen found ${ }^{1}$ inflammatory changes in 35 of 46 joint capsules $(76 \%)$. Amyloid tended to be negatively correlated with inflammation in both the present investigation and their study. It can be seen from Table 2, where results from the 2 studies are combined, that in 58 of the joint capsules with severe and moderate inflammation only 9 were found to be amyloid-positive $(15.5 \%)$ and that in 104 joint capsules with little or no inflammation $35(33.6 \%)$ showed amyloid degeneration $\left(\chi^{2}\right.$ test. $0 \cdot 02>p>0 \cdot 01)$. This finding, incidentally, is also in good agreement with the biphasic theory suggested by Teilum for the formation of amyloid. ${ }^{25} 26$

Teilum advanced the so-called biphasic cellular theory concerning the pathogenesis of amyloid deposition. In histochemical studies on caseinateinduced amyloidosis in mice the amyloid was found to be present as a product of periodic acid Schiff (PAS)-positive reticuloendothelial cells in situ. A primary, pyroninophilic phase, with proliferation of pyroninophilic cells and an increase in serum globulin, is followed by a secondary amyloid phase with inhibition of the pyroninophilia and the occurrence of PAS-positive reticuloendothelial cells in the marginal zone of the amyloid aggregates. The PASpositive cells perish immediately after local amyloid synthesis has taken place.

Finally, amyloid in osteoarthritic hip joint capsules is significantly positively correlated with chondroid 
metaplasia and pyrophosphate deposits, while it is significantly negatively correlated with the amount of inflammatory cell infiltration. As regards chondroid metaplasia, further investigation is under way in our laboratory to decide whether the chondrocytes are responsible for the production of amyloid either by direct synthesis or by liberation of an amyloidinducing substance.

\section{References}

1 Christensen H E, Sørensen K H. Local amyloid formation of capsula fibrosa in arthrosis coxae. Acta Pathol Microbiol Scand (A) 1972; suppl 233: 128-31.

2 Cohen A S, ed. Laboratory diagnostic methods in the rheumatic disease. Boston: Little, Brown, 1975: 295-412.

3 Puchtler H, Sweet F, Levine M. On the binding of Congo red by amyloid. J Histochem Cytochem 1962; 10: 355-64.

4 Shirahama T, Cohen A S. High resolution electron microscopic analysis of the amyloid fibril.J Cell Biol 1967; 33: 679-708.

5 Bernhard G C, Hensley G T. Amyloid arthropathy. Arthritis Rheum 1969; 12: 444-53.

6 Bywaters E G L, Dorling J. Amyloid deposits in articular cartilage. Ann Rheum Dis 1970; 29: 294-306.

7 Gamarski J, Netto M B. Manifestagoes osteo-articulares na amyloidose primaria-apresentaqoe de caso. Arch Interamer Rheumatol 1959; 2: 651-63.

8 French B T. Amyloid arthropathy in myelomatosis-intracytoplasmic synovial deposits. Histopathology 1980; 4: 21-8.

9 Kavanaugh J H. Multiple myeloma, amyloid arthropathy and pathological fractures of the femur.J Bone Joint Surg 1978; 60A: 135-7.

10 Kruse P. Amyloid artropati. Ugeskr Lager 1971; 133: 1777-9.

11 Pruzanski W, Hasselback R, Katz A, Parr D M. Multiple myeloma (light chain disease) with rheumatoid-like amyloid arthropathy and my-heavy chain fragment in the serum. Am J Med 1978; 65: 334-41.
12 Chapman W L, Crowell W A. Amyloid in rhesus monkeys with RA and enterocolitis. J Am Vet Med Assoc 1977; 171: 855-8.

13 Linke R P, Kønig G. RA und Amyloidose. Diagnostische Signifikanz eines löslichen, synoviale Proteins mit immunologischer Kreuzreaktion mit dem Amyloid Fibrillen Protein A. Verh Dtsch Ges Rheumatol 1978; 5: 330-3.

14 Pasternack A, Tiilikainen A. HLA-B27 in RA and amyloidosis. Tissue Antigens 1977; 9: 80-9.

15 Teilum G, Lindahl A. Frequency and significance of amyloid changes in RA. Acta Med Scand 1954; 149: 449-55.

16 Sørensen $\mathrm{K} \mathrm{H}$, Christensen $\mathrm{H}$ E. Local amyloid formation in the hip joint capsule in osteoarthritis. Acta Orthop Scand 1973; 44: 460-6.

17 Ladeford C, Christensen H E. Congophilic substance with green dichroism (CS-GD) in hip joints in autopsy material. Acta Pathol Microbiol Scand (A) 1980; 88: 55-8.

18 Franklin H S, Dahlin D G, Ivins J C. Extraarticular synovial chondromatosis. J Bone Joint Surg 1977; 59A: 492-5.

19 Tegelbjærg P S, Ladefoged C, Sørensen K H, Christensen H E. Local articular amyloid deposition in pyrophosphate arthritis. Acta Pathol Microbiol Scand (A) 1979; 87: 307-11.

20 Villacin A B, Brigham L N, Bullogh P G. Primary and secondary synovial chondrometaplasia. Hum Pathol 1979; 10: 439-51.

21 Ladefoged C. Amyloid deposits in human hip joints. A macroscopic, light and polarization microscopic and electron microscopic study of congophilic substance with green dichroism in hip joints. Acta Pathol Micrbiol Scand (A) 1982; 90: 5-10.

22 Ladefoged C, Christensen H E, Sørensen K H. Amyloid in osteoarthritic hip joints. Depositions in cartilage and capsule. Semiquantitative aspects. Acra'Orthop Scand 1982; 53: 587-90.

23 Ladefoged C. Amyloid in osteoarthritic hip joints. A pathoanatomical and histological investigation of femoral head cartilage. Acta Orthop Scand 1982; 53: 581-6.

24 Bjelle A, Sundén G. Pyrophosphate synovitis. Acta Orthop Scand 1971; 42: 131-41.

25 Teilum G. Pathogenesis of amyloidosis. The two phase cellular theory of local secretion. Acta Pathol Microbiol Scand $(A)$ 1964; 61: $21-45$.

26 Teilum G. Origin of amyloidosis from PAS-positive reticuloendothelial cells in situ and basic factors in pathogenesis. In: Mandema E, Ruinen L, Scholten J H, Cohen A S, eds. Amyloidosis. Amsterdam: Excerpta Medica, 1968: 37-44. 